\title{
Phenolic content and antioxidant activity of cantaloupe (cucumis melo) methanolic extracts.
}

\begin{abstract}
The objectives of this study were to determine phenolic content and antioxidant activity of methanolic extracts from different parts of cantaloupe (leaf, stem, skin, seed and flesh). The flesh extract afforded the highest yield $(89.6 \pm 0.3 \%)$ whilst the lowest yield was obtained from the seed $(13.7 \pm 0.5 \%)(\mathrm{p}<0.05)$. The leaf extract showed the highest total phenolic content $(26.4 \pm 0.3 \mathrm{mg}$ GAE/g extract) and total flavonoid content $(69.7 \pm 3.37 \mu \mathrm{g} \mathrm{RE} / \mathrm{g}$ extract) accompanied with best antioxidant activity through all antioxidant assays ( $\mathrm{p}<0.05)$. In addition, the stem extract also exhibited good antioxidant activity. Thus, these results suggest that methanolic extracts of cantaloupe leaf and stem may serve as a potential source of natural antioxidant for food and nutraceutical application.
\end{abstract}

Keyword: Cantaloupe; Methanolic extraction; Total phenolic content; Total flavonoid content; Antioxidant activity 